DOI: $10.1515 /$ ausfm-2018-0004

\title{
Roy Andersson's Tableau Aesthetic: A Cinematic Social Space Between Painting and Theatre
}

\author{
Fátima Chinita \\ Lisbon Polytechnic Institute, Lisbon Theatre and Film School (Portugal) \\ E-mail: chinita.fatima@gmail.com
}

\begin{abstract}
The article examines three films by Roy Andersson, Songs from the Second Floor (Sånger från andra våningen, 2000), You, the Living ( $\mathrm{Du}$ levande, 2007), and A Pigeon Sat on a Branch Reflecting on Existence (En duva satt på en gren och funderade på tillvaron, 2014). The Swedish director depicts the human condition afflicted by the loss of its humanity through a personal style that he calls "the complex image," a tableau aesthetic that instigates social criticism, and is dependent upon long shots, immobility, unchanging shot scale, and layered compositions. The author establishes a connection between artistic and social space and scrutinizes the challenges that this "complexity" poses for the film viewer from an intermedial perspective in which cinema enters into a dialogue with two other art forms: painting and theatre. Four specific issues are discussed: (1) the intertwining of reality and artificiality as a "hyperreality;" (2) the visual compositions which are simultaneously self-contained and entirely open, highlighting a tension between volume and surface; (3) the opposition between stasis and movement, conveying a meaningful social contrast and the characters' angst; (4) the pictoriality of the image. ${ }^{1}$
\end{abstract}

Keywords: tableau aesthetic, inter-art relations, complex image, space, Roy Andersson.

\section{Andersson's Complexity: Humanism Posited as Artistic Illusion}

Roy Andersson's so-called Living Trilogy, about the human condition, comprises the films Songs from the Second Floor (Sånger från andra våningen, 2000), You, the Living (Du levande, 2007), and A Pigeon Sat on a Branch Reflecting on

1 This article was financially supported by FCT, Portuguese state Foundation for Science and Technology, under the Post-Doctoral fellowship programme SFRH/BDP/113196/2015. 
Existence (En duva satt på en gren och funderade på tillvaron, 2014). ${ }^{2}$ It is meant to be a challenging experience for film viewers, both from an aesthetic and an ideological perspective.

The director's working-class background and his left-wing political sympathies have always made him an advocate for the powerless and disenfranchised; his humanist ideology exposes the dystopia that ensues when people neglect their humanity. He made cinema's subversive role an important part of his ideology, directly connecting art to life. He declared in an interview that "humanism's ideal of perfection is the educated person, who acknowledges the value of the truth over every authority. To seek the truth - in the form of artistic expression, scientific knowledge, or philosophical insight - is to develop our humanity" (Lindqvist 2016, 120). In his book Our Time’s Fear of Seriousness (Vår tids rädsla för alvar, published in Swedish in 1995), Andersson posits that as an instrument of social criticism a more "serious" type of filmmaking is needed. An aesthetics, which Andersson calls "the complex image," (Larson and Marklund 2010, 27478) is deemed essential to criticize all forms of the establishment, including the military, the church, financial corporations, and the film industry itself.

Andersson's "complex image" is characterized by a kind of minimalism: from the dramaturgy to the space, all is intentionally spare and precise. The shots are long, elaborately framed in a wide composition and extreme depth of field (which keeps all the objects and people in focus all the time, often requiring the use of trompe l'œil backgrounds); immobility is prevalent, since the characters' movements are reduced to near stasis and the camera, too, rarely moves; the shot scale is consistently maintained and the image composition is deeply layered. The pace is languorous, the characters are archetypes that hardly speak, or utter banalities; the story does not proceed by cause and effect; narrativity is conveyed, rather, through analogies and repetitions (thematic, visual, musical, and verbal), instead of having a conventional plot. The settings are scantily decorated and there is a pervasive sense of abstraction.

Andersson's "complex image" is in fact a tableau aesthetic that deliberately makes the viewers think about the conditions of art and life, and is based on tableaulike shots - as defined by Brewster and Jacobs (1997) -, in which situations are presented in a relatively large space and relatively long temporal units, reminiscent of theatrical pictorialism, but with the added value of near immobility inherited from painting. In Andersson's cinema, the imminently self-reflexive nature of this style, ironically, expresses the vitality of art as opposed to the lifeless society it

2 For the sake of economy, I will refer to them from now on by the first word of their English title. 
depicts. In what follows, I intend to establish a connection between artistic and social space, and to scrutinize the challenges that this intrinsic and polymorphous "complexity" poses for the film viewer from an intermedial perspective in which cinema enters into a dialogue with other art forms.

\section{Truth be Told: Social Space and Artistic Freedom}

Space is what ties together all the formal and ideological elements implicit in Andersson's aesthetic. According to the filmmaker, human beings cannot free themselves from the space they inhabit. In a pictorial representation, it is space that reveals an individual's destiny as well as his or her position in society (Girola and Fornara 2003, 7-8). Space also has a tragic tone, as it can convey a feeling of "forsakenness" and "vulnerability" (Spiegland 2010). The director himself claims that "the space tells the truth" more than the human face does (Girola and Fornara 2003, 8, my translation); "for example, the room where the person is tells about his tastes, his life. Even if it's not home, you can read the history of a person better in a wide shot" (Vishnevestsky 2009).

The settings of all three films are generally urban. Many are perceived as being spacious, due to the depth of field, the wide shot, the wide-angle lens, and the scarce number of people that inhabit them. Others convey an opposite impression, that of claustrophobia, mainly because of the immobility of groups of people who are usually packed into one area of the image, leaving the rest of the frame unpopulated. In either case, Roy Andersson's worlds are predominantly what Marc Augé calls "non-places:" abstract and universal sites lived in a neverending present, devoid of history and human relations, filled with signs of an evanescent temporality (Augé 1995, especially 90). These sites are characterized by consumption (bars, restaurants, shops), circulation (train stations, bus stops, trams, streets, an airport check-in area, a cruise ship), spectacle (festivities, music or magic shows, dance or rehearsal studios), and anonymous passage (clinics, hospitals, resting homes). The use of such places reinforces the fate of humans, condemned to a perpetual loneliness. [Figs. 1-2.]

In one situation in $\mathrm{You}$, a man standing on a balcony looks at the opposite façade of an apartment building, where he sees, in a wide composition reminiscent of Alfred Hitchcock's film Rear Window (1954), a tenant striking the ceiling with a broom in order to try to silence the upstairs neighbour, who is rehearsing his tuba-playing skills at night. [Figs. 3-4.] The man just looks nonchalantly at this scene, himself becoming a spectacle just like the one he is observing, all the 
more so because he is perceived from within the house by his own wife, who addresses him off-screen, remaining unseen by the viewer. This perfectly echoes Augé's remark: "as if the position of spectator were the essence of the spectacle, as if basically the spectator in the position of a spectator were his own spectacle" (Augé 1995, 70). This spectatorial stance in the trilogy is reinforced by the fact that, in many tableaux, there are people conspicuously looking on.

The trilogy shows that all human beings are affected by the spaces in which they live (Tuan 1977, 3). According to Yi-Fu Tuan, however, space is undifferentiated and only becomes a place when it is endowed with value by human beings (1977, 6, 136). Andersson's spaces, which are non-descript, mostly empty and monochrome, do not have the aura imparted by familiar places, as conceived of by Tuan $(1977,4)$. Yet, in the Living Trilogy this cannot be attributed, as Augé contends with regard to non-places, to a supermodern contemporaneity, since the films are not anchored in any specific historical time. However, there are some marks of the transience of supermodernity in order to remind the viewers of the impossibility of developing roots and establishing successful long-term relationships. For example, in Songs, a vagrant makes a comment on an enormous traffic jam: "it seems the whole town is on the road. Everyone in the same direction. It makes you wonder where they're headed, you know, the people." ${ }^{3}$ Despite going in one single direction, humanity is metaphorically lost. Non-communication reigns supreme, as in a situation in Songs in which a mildlooking Middle Easterner male is beaten senseless by a group of young ordinary Nordic men while some people watch passively from afar.

Most importantly, in Andersson's trilogy the unlived-ness of the sites extends to the home, which attests to the moral malformation of humanity in these films. Ironically, in Swedish, the welfare state, one of the targets of Andersson's social criticism, is known as "the people's home" (folkhemmet). The home, considered by Tuan $(1977,182)$ as the most intimate, inviting and symbolic place of man, is a privileged locus for non-communication throughout the trilogy. This is most evident in almost all of the couples' interactions, which are completely devoid of tenderness. In Songs, for example, an old clerk refuses his wife's sexual advances because he has to go to work $;^{4}$ in You, a man exercises on a treadmill in his basement, ignoring his young son who wants to play with him. Besides all else, the scarcity of interior decoration renders the home devoid of any individuality:

3 All quotations from the films are from the Artificial Eye editions of the DVDs, and so are the figures at the end of this article.

4 In contrast, in You, an old musician has mechanical sex with a Valkyrian-like matron, possibly in a hotel room, all the while speaking straight to the camera about financial matters. 
as a result, every house seems exactly the same. Thus, the anthropological places, where people are supposed to create roots and develop activities characteristic of their identity as human beings, are irreversibly flawed. Due to the tableau aesthetic adopted by Andersson in the trilogy, space is never humanized into "place." On the contrary, the surplus of space in the settings highlights the lack of humaneness in people, as it stresses distance and the invisible barriers that separate individuals. The low mobility that pervades most tableaux reduces kinaesthesia and, coincidentally, makes the spaces seem larger than they actually are. It also gnaws at the sense of physical direction, which comes from moving in space (Tuan, 1977, 12) and without which it is difficult to have a notion of existential direction, goals to accomplish (Tuan 1977, 197, 128).

Ideologically, Andersson's style is marked by "trivialism," in which all the banal moments that make up the sum of this grim humanity conjoined with the impersonal space it inhabits are meant to give "a voice" to the little people who symbolize mankind as a whole (Ratner 2015, 2). He does this by elevating these moments to high art instead of letting them fall into burlesque. His human gallery is pathetic, but treated with respect and commiseration, not turned into a comic target of mindless derision. This is why the trilogy is tragicomic, marked by absurd contrasts occurring within the tableaux, i.e. within space. The fact that Andersson has the great majority of his settings built from scratch, including train stations and streets, is unintendedly ironic in that the most innovative results, apparently, come from a rigid, almost obsessive preparation. More than controlling the environment, in a shooting which entails blocking many extras and guaranteeing the right lighting conditions, the use of studio-built spaces conveys an artificiality - "hyperreality," as Andersson calls it ${ }^{5}$ - which highly resembles painting (as well as theatre) and transforms Andersson's cinematic practice into a fully intermedial one.

\section{Infinite Boundaries: In-Depth Flatness}

Art has a special signification for Andersson. He is a jazz lover who plays trombone and guitar, has authored two books, and, most importantly, wanted to be a painter, professing, to this day, his admiration for that art form: "I am often very jealous of painting. Jealous because I feel that movie history does not have the same quality as painting history. I really wanted movies to be as rich as painting can be" (Ratner 2015, 12). This comment, and others like it, helps to establish an immediate 
connection between Andersson's tableaux and pictorial canvases. Jesper Klevenås, one of the two cinematographers of Songs, referred to the filmmaker's practice as "three-dimensional paintings" (Lindqvist, 77). I endorse this evaluation, but it seems to me that it should be scrutinized from the perspective of media specificity and co-option, rather than mere intertextuality, as is often the case (e.g. in Lindqvist 2016). Therefore, I claim that the second challenge posed by Andersson's use of the tableau aesthetic in this trilogy resides in the reinforced use of pictorial framing as he is always positing the visual composition as being simultaneously self-contained and entirely open.

Julian Hanich (2014), in an extremely thorough and well-rounded analytical piece on Roy Andersson's compositional system in the Living Trilogy, posits the matter in terms of staging in depth. Although I agree that "Andersson challenges his viewers to become attentive observers" (Hanich 2014, 37), I contest the fact that the depth of field is the key element in his "complex image" technique. Instead, I argue that depth of field is only important inasmuch as the whole visual field is in focus for as long as possible, and provided that there is as wide a space as is technically feasible. ${ }^{6}$ We should consider all the aspects contained in an Anderssonian complex image. I contend that Andersson's complex image calls attention to a game of dimensionality, a tension between volume and surface which is connected to the director's intermedial appreciation of painting and the static impression it holds.

In film, a composition in depth is usually perceived as the extension of the visual field. This conception is highly dependent on the diegetic world and its confines, the borders which separate the on- from the off-screen space, but with the frame reference of the so-called reality in mind. André Bazin, for instance, argued that cinema was the most complete of all the art forms because it could provide "integral realism, a recreation of the world in its own image" (Bazin 1967, 21). Bazin held cinema in higher esteem than painting because, in his opinion, the former's photographic nature secured "objectivity in time" (1967, 14) by halting a certain moment in its duration and, therefore, laying reality bare, as an impression; whereas the latter offered an "illusion" $(1967,12)$ which was a mere likeness to reality, further affected by the input of the artist. Bazin's partiality towards cinema led him to consider the cinematic and the pictorial frames differently. For him, a screen frame was centrifugal, prolonging the view

6 According to David Bordwell, there is a clear difference between depth of staging, which is a spatial property of the setting, and depth of field, which is an optical characteristic. For that reason, it is preferable to use the expression "deep focus" when referring to the latter factor. Cf. Bordwell 1997, 158-271. 
"indefinitely into the universe" (i.e. the real), whereas the picture frame was centripetal, providing "a contemplative area opening solely onto the interior of the painting," i.e. the artwork (Bazin 1967, 166).

Andersson's tableaux are almost all framed the same way, obeying very precise and personal rules of composition in order to introduce depth into pictorial twodimensionality. Linear perspective has, from the Renaissance onwards, imposed on the viewer a sense of three-dimensionality. This visual space is imaginary, but it is nonetheless based on natural perception, i.e. the way the beholder sees the world. Art historian E. H. Gombrich (1982) warns of the fallacy of considering that linear perspective is realist; the pro-realist Bazin even considered it "the original sin of Western painting” $(1967,12)$, thus recognizing its intrinsic artificiality. Andersson uses perspectival depth in order to further reinforce artificiality, instead of endowing his tableaux with straightforward realism. Shooting in front of facades is a way for him to stress the surfaces and, at the same time, add a sense of volume. Perhaps the most radical example of this occurs in A Pigeon, when a little girl is seen on a balcony blowing soap bubbles into the air. The image is flat and composed horizontally, but, through an open door placed behind her, we perceive another little girl inside the house (in the background), who soon joins her outside (in the foreground). [Fig. 5.]

The contiguity of spaces is a recurrent feature in Andersson's tableau aesthetic. The vast majority of tableaux throughout the trilogy are framed in such a way that they extend into two adjoining spaces: doors open towards another room or a kitchen, windowpanes reflect the opposite or neighbouring buildings, and shop windows reveal what is taking place outside in the street. Usually two of such spaces are perceived in one single shot, either in depth or laterally. For instance, in You, a daughter visits her old demented mother in a nursing home: both the mother and the daughter are seated in the foreground of the image, a nurse stands by an open glass door letting the film viewers see, beyond it, a large living room and, even farther away, the windows with their curtains giving onto the neighbouring buildings. [Fig. 6.] The lack of movement in the space is thus compensated by the eye movement of the viewers, wandering through several image layers and the frames-in-the-frame they contain. Thereby, an impression of centrality is often conveyed, emulating Renaissance painting. The composition of Andersson's tableaux is commonly frontal, even when the films allude to beings or objects placed somewhere higher-up: people on the upper floors of buildings, in an allusion to the second floor of the film's title in Songs; bombers in the sky at the opening and closing of You; and birds perched on the trees of A Pigeon. Even 
when the camera is placed at an angle to a building, the main human character occupies the middle of the frame. That is the case with the commander in $A$ Pigeon, who watches the diners at a restaurant delight in their meals while he stands outside, hopelessly lonely, waiting for a meeting that will not take place [Fig. 7], but this has other implications as, in fact, the accentuated perspective only contributes further to the artificiality of the composition.

Gregory Minissale claims that a self-reflexion from inside the painting (such as an inner frame) may call our attention to the frame itself "in a process activated by the visual experience of framing in art" (Minissale 2009, 20). Consciousness of the frame must be obliterated in order for the spectator to concentrate on the visual content of the canvas and not the canvas itself. Nevertheless, in some cases there is an inevitable rebound movement between the confines of the painting and its interior: "the centre disperses consciousness outwards to an ideal point from where it must return; the frame or edge are continually signalled by this rebounded consciousness" (Minissale 2009, 21). Andersson's compositions highlight the resemblance with painting. In A Pigeon, for example, a man stands outside a delicatessen and contemplates the building opposite, which is reflected in his own shop window, then he looks at the camera and says, "today I feel kind. Damn kind." Inside the shop, arranging some cheeses in the window display, a woman looks straight at the camera and signals with her hand that the man is crazy. [Fig. 8.]

The shot composition is static, as is the man on the threshold, and yet the film viewer cannot help but feel a rebounding movement in the image, whose limits, or frames, are exceeded twice: intra-diegetically (or centripetally, in the reflection of the other buildings) and extra-diegetically (or centrifugally, by implicating the film viewer in the scene through the diegetic gaze). Andersson makes the viewer be simultaneously aware of the inside and the outside of the film. According to Jacques Aumont, this is a weaker form of awareness, (Aumont 2007, 194). The viewers mainly watch the fictive space of representation but cannot avoid being aware of the means through which the illusion comes to pass. In the continuity editing style of classical cinema there would never be enough time, or sufficient lack of movement to allow for the rebounding to take place in stages, as it does in the perception of painting.

Although chronological perception is foremost associated with film, which is experienced in a flux of shots, the viewer's eye gazing upon a painting can perceive its content in separate areas, which may correspond to separate moments as well. However, in painting there is no hint of order provided by intra-diegetic movements; the spectator's eye wanders (almost) freely. Andersson manages to 
make the most of both media and provide a pictorial composition in depth with inner cues. For example, the bar where the salesman of Songs appears for the first time is placed on a street corner overseeing a crossroads which enables the viewer to see through the large shop windows a traffic jam of gargantuan proportions. The viewer simultaneously apprehends the sad tale of personal bankruptcy that the man recounts to the barmaid at the counter and the chaos of the honking cars outside. A woman dressed in brown, who comes and goes, helps the viewer to adjust his or her sight to the inside or the outside of the bar, concentrating on a particular area of the image at a given moment. In the unstoppable narrative film flux, the movement of characters on-screen helps to guide the viewer with utmost economy and efficiency, considering the limited time allotted by the editing. In Andersson's very static tableaux the time provided for the viewer's perception is longer than it usually is in most conventional narrative films.

\section{The Instant that Lives on: Static Motion}

From a formal standpoint, the Living Trilogy foregrounds the tension between stasis and movement contained in any tableau composition. The conjoined use of motion and stasis, together with duration and instant, is what makes Roy Andersson's cinema so original in intermedial terms, not his power of quotation or appropriation of sources. This is the third complexity involved in Andersson's tableau aesthetic.

It is Diderot's stage conception of the tableau vivant, as described by Michael Fried, which is closer to Andersson's use of his own complex image: "tableaux (visually satisfying, essentially silent, seemingly accidental groupings of figures)" (Fried 1980, 78). For Diderot, "the spectator in the theatre ought to be thought of as before a canvas on which a series of such tableaux follow one another as if by magic. [...] Accordingly, he stressed the values of pantomime as opposed to declamation, of expressive movement or stillness as opposed to mere proliferation of incident" $(1980,78)$. Such subdued representations are at the core of Andersson's dystopic worlds in the Trilogy.

By adopting some aspects of the theatrical stillness form in his own cinematic praxis, Andersson reinforces the inert nature of his spaces and characters, rendering immobility more pregnant through both media's capability for movement, and also stressing duration more effectively as part of an action that evolves in time. Andersson, basically, rejects the exaggeration that Diderot pejoratively called "theatricality," but, like him, retains the importance of a chosen instant that acts 
as a condensed representation of the essence of a scene, conveniently signalled by the actors' transient group immobility. The main difference between Andersson and Diderot in this respect is that in the complex image the chosen moment is undramatic, albeit representative. Diderot's "pregnant moment[s]" were apotheotic, whereas Andersson's slices of life are anticlimactic. For example, in A Pigeon, a few people are waiting for a bus right in front of a bicycle repair shop and never change their position during the entire time of the tableau (2:46 minutes). [Fig. 9.] The owner of the shop comes out and says that it is Wednesday again, which causes the man closest to the bus sign to say that it feels like Thursday, which in turn, prompts the others to set him right about which day it is. A man who is in the background attending to his tires leaves the frame, and then a pigeon is heard singing higher up, off-screen, indicating that the most pregnant action is probably taking place outside of the visual composition and is inhuman; people just stand around not doing much.

Notice that it is painting, and not theatre, that is ultimately underlined by the conjunction of stage and screen, as Fried's simile reveals ("thought of as before a canvas"). However, the pictorial effect in the trilogy would not be possible without the performative influence of theatre. Even the white make-up covering most of the characters' faces, in order to unite them in a pathetic brotherhood of Everymen, looks like a softer version of a mime's appearance. Stasis and movement can just as equally occur in theatre and be inferred in painting. There is an uncanny quality that results from the animation of a painting, as much as from the halting or prevention of motion in essentially three-dimensional performances. This juxtaposition reminds us that painting has always striven to represent movement, while theatre has tried to present the scene as a frame to be looked at. Lessing even used the expression "pregnant moment" in his Laocoon. An Essay Upon the Limits of Painting and Poetry $(1887,92)$ in reference to painting and not to theatre.

Diderot's and Lessing's "pregnant moment" is actually a pre-condition of human cognitive experience in general and not of art appreciation per se. It is not possible to make sense of the world (and art) without a very short span memory which keeps present, at once, things which have gone before (and are still retained in the memory for an instant) and things which will come after (culture and habit make us prone to the evocative power of images and, therefore, trigger expectations) (Gombrich 1982, 7, 272). Gombrich claims that "visual perception itself is a process in time, and not a very fast process at that" $(1982,50)$. Lessing also conceives time and space as being interconnected. For him the bodies 
depicted side by side in a painting belong to both dimensions: "they continue, and, at any moment of their continuance, may assume a different appearance and stand in different relations. Every one of these momentary appearances and groupings was the result of a preceding, may become the cause of a following, and is therefore the centre of a present, action" (Lessing 1887, 91-92).

This accords well with Gombrich's notion that actions in painting can be, at the same time, represented as being consecutive and simultaneous $(1982,43)$. In Andersson's tableau aesthetic the whole is perceived along with its parts. The tableaux and the actions depicted in them are apprehended simultaneously and consecutively and, since they are moving pictures, the effect is even more pronounced than in painting.

Julian Hanich is right in saying that Roy Andersson's films are not completely static: "the temporal dimension of cinema allows Andersson to reveal elements progressively and let facets of the shot appear unexpectedly" (Hanich 2014, 48). Hanich refers to the gags and other surprise effects that permeate the trilogy, but there are also other features to consider. On the one hand, all images, including paintings and photographs, can imply movement, as Gombrich indicates in several of his writings; and, on the other hand, the paradoxical nature of Andersson's complex image, in fact, requires that the images move in all tableaux in order to establish a meaningful contrast. For example, in You, a small crowd gathers to shelter from the pouring rain in the ridiculously small space of a covered bus stop. [Fig. 10.] The viewer's eye has time to discern the bus stop, in the middle of the frame, and then to perceive the other people looking out of their windows in the background. Two sets of people, who have been discovered consecutively, are standing still simultaneously. Then another man appears in the middle ground of the image, seeking cover from the rain; he moves back and forth before exiting the frame. In view of this intensified motion, the stillness of the other characters is made even more prominent - in physical as well as in social terms - as the unprotected man is made to symbolize the social underdog. The tableau thus means that while some take cover, others get wet. Rudolf Arnheim observes that movement in a frame is perceived by the viewer differently depending on a hierarchy of visual elements pertaining to the background, size, shape, contiguity, and formal intensity. The figures concentrate the viewer's attention and, in comparison, the background seems motionless; objects which change size or shape seem more active than others, as does one of two objects standing side by side, etc. (Arnheim 1980, 372373). This means that space is not steady and cannot be correctly apprehended without the property of motion. 
Inside a painting time is never still, everything is changing, even if ever so slightly. Élie Faure, writing on the plasticity of cinema in 1920, stressed its combination of movement and space. Duration conveyed through the images inside the frame is a rich resource both in cinema and painting, but in Faure's opinion, the physical animation of the image in film (i.e. intrinsic movement) elevates cinema above painting (Faure 2010, 21-23). Andersson uses this to his advantage. Indeed, the expressive force contained in one of You's tableaux, in which the passengers of a tram descend at a stop, would not be possible in painting. In this tableau the tram, bound for "Lethe" (one of the rivers in the Greek mythical underworld of Hades), opens its rear door and a stream of people pours out of it. The overall composition and the tram are perfectly still, but a never-ending flow of passengers - far exceeding the capacity of the vehicle - descends. [Fig. 11.] Taken literally, the scene is nonsensical, but the increased movement of the passengers bestows a certain mechanical feeling upon the image and, therefore, an added dimension of social criticism. In this case, length is reinforced because of motion; without it the tableau would be merely descriptive and would lose the force that comes from the "lingering" of the shot (see also Yang 2013, 48).

The way in which the speed of actions and gestures is perceived by the viewer also depends on the mood and emotional state experienced by the characters (Gombrich 1982, 81). In the Living Trilogy, social angst is conveyed through the depiction of space in time. The angst experienced by the characters is multiplied many times in the viewer, as a sort of emotional rebounding effect. In the beginning of A Pigeon, for example, a man is looking out the window as if absorbed in his thoughts, the table is set for dinner and his wife is preparing the meal in the kitchen while singing, totally oblivious to what is going on in the next room. [Fig. 12.] The man, always silent and alone, strives for a while to open the wine bottle and finally collapses to the floor, seemingly suffering a heart attack from which he dies. The lack of marital communication is transformed into a painful feeling of impotence for the viewer; the outcome is to be expected (the tableau is titled "Meeting with Death no. 1"), but the experience is anguishing because the low motility seems to expand time, and place the two contiguous rooms farther away from each other. The fact that the status quo of the scene does not change - that the other character that inhabits the frame does not move in order to prevent the situation in the foreground from taking place - contributes in no small measure to a feeling of static motion.

If all still images can convey movement, all moving images can likewise be arrested. For instance, in a single tableau of You, a uniformed marching band 
plays in a square for a while and then leaves the frame while a small crowd of spectators remain perfectly still instead of disbanding. In a less painterly film the shot would probably come to an end with the exiting of the band; as it is, the viewer is made to watch a non-event for a while. [Figs. 13-14.] Thus, dead time is responsible for dead space as well and, consequently, for the perception of a metaphorically dead humanity.

\section{Still Life: The Aesthetics of Immersive Awareness}

What seems to attract Andersson the most in painting is precisely its profoundly immersive nature for the beholder: "it is fantastic that a person can stand for a long time and look at a single painting, isn’t it?” (Lindqvist 2016, 97). Paintings, especially when figurative and composed according to perspectival rules, elicit contemplation because they are actions or situations condensed in a single frame: the beholder strives to perceive what was left out of the canvas, the story that led up to that moment. The vividness of some depictions also calls for a setting in motion of the scene. Indeed, just as Michael Fried (1980, 49-53) considers that Jean Siméon Chardin's canvases, especially the ones depicting children performing ludic activities are meta-pictorial in that they, at once, betray a selfconsciousness of the painter's own feelings for painting and his wish to absorb the beholder, so can Roy Andersson's tableaux exercise the same double function. This is the fourth complexity contained in Andersson's tableau aesthetic.

The filmmaker's intended immersion works differently than the one posited by Denis Diderot for painting. Andersson does not wish to awake intense passion and extreme emotions in the viewer, nor does he want to convey such passions and emotions of his own rather sedate and alienated human gallery. These figures may be immersed in contemplation, but that state is not meant to be perceived as joyous by the beholder. Andersson's tableaux are, nevertheless, instantly apprehensible as pictorial images consisting of a single action, ${ }^{7}$ charged with morality, and organized for a beholder to see, as are those of Diderot (Fried 1980, 76, 84). He also wants to "make virtue sympathetic, vice detestable and ridiculousness quite perceptible" (Fried 1980, 80). I contend that the tension between the activity of seeing (i.e. the way the tableaux grab the viewer), and the objects/subjects that are seen (i.e. the pictoriality inherent in painting and also applicable to theatre) is the key for Andersson's authorial discourse as an artist. Uniting a particular arthouse cinematic form with a specific social ideology has already granted Andersson a

7 In Andersson's trilogy that action is eminently pathetic rather than heroic. 
special place in the history of cinema, but beneath that auspicious conjunction lies yet another level of meaning, a meta-artistic stance on the properties of the cinematic medium and its relationship to other art forms.

Although André Bazin considered the long take a very natural and life-like process $(1967,33)$, Andersson's use of it far exceeds the Bazinian refusal to break up the action. In fact, the Swedish director's practice contradicts the first of Bazin's postulates on the long take: "therefore it is correct to say that, independently of the contents of the image, its structure is more realistic." Andersson does not "chop up" the world into little fragments, as Bazin (1967) understands classical editing, but he is no less one of "those directors who put their faith in the image" (Bazin $1967,24)$, instead of the real. His style is very contrived as he emulates pictoriality above all else, stressing the fact that reality is never represented as it is (in pictorial arts, the standards of truth are intrinsically corrupted) (Gombrich 1982, 244-246) and that "representation is not defined by imitation" (Barthes 1977, 69). For Barthes, cinema, theatre and painting are "direct expressions of geometry" because, visually, their existence is dependent upon a cut-out rectangle, which is not an extension of the real world. The tableau is a frame and all that it contains is "laid out" for the viewers to see (Barthes 1977, 70-71). Contrary to Bazin's idea that cinema by being photographically produced was centrifugal, Andersson proves that cinema can also be centripetal and makes that absorptive quality the basis of his reversed immersiveness. The more the viewers perceive the illusion, the more they want to concentrate on it and analyse it as a spatial art object. In the Living Trilogy spatial homogeneity is a magic trick which reveals the absurdity behind reality.

\section{References}

Arnheim, Rudolf. 1980 [1954]. Arte e Percepção Visual: Uma Psicologia da Visão Criadora [Art and Visual Perception: A Psychology of the Creative Art]. São Paulo [etc.]: Pioneira Thomson Learning.

Augé, Marc. 1995 [1992]. Non-Places: An Introduction to Supermodernity. London and New York: Verso.

Aumont, Jacques. 2007. L'CEil interminable [The Endless Eye]. Paris: Éditions de la Différence.

8 This is all the more interesting as Andersson confesses an appreciation for Bazin's writings and namely the two other conditions established by the French theoretician in the article 'The Evolution of the Language of Cinema:' mental activity on the part of the spectator and ambiguity of expression. Andersson claims that Bazin "put words to what I was doing" (Johanna Grönqvist 2000, quoted by Yang 2013, 47). 
Barthes, Roland. 1977 [1973]. Diderot, Brecht, Eisenstein. In Image, Music, Text, 69-78. New York: The Noonday Press.

Bazin, André. 1967. What Is Cinema? Berkeley [etc.]: University of California Press.

Bordwell, David. 1997. On the History of Film Style. Cambridge, MA and London, UK: Harvard University Press.

Brewster, Ben and Lea Jacobs. 1987. Theatre to Cinema: Stage Pictorialism and the Early Feature Film. Oxford and New York: Oxford University Press.

Dagliden, Jonna. Roy Andersson: 'I'm Trying to Show What It's Like to be Human.' The Guardian, August 28, 2014. https://www.theguardian.com/film/2014/ aug/28/roy-andersson-pigeon-sat-branch-reflecting-existence. Last accessed 16. 09. 2017.

Faure, Élie. 2010 [1920]. De la cinéplastique. In Cinéma, cinéma, cinéma, 11-35. Houille: Éditions Manucius.

Fried, Michael. 1980. Absorption and Theatricality: Painting and Beholder in the Age of Diderot. Chicago and London: University of Chicago Press.

Girola, Fiammetta and Bruno Fornara, eds. 2003. Roy Andersson. Bergamo: Ventunesima Mostra Internazionale del Cinema d'Essai.

Gombrich, E. H. 1982. The Image and the Eye: Further Studies in the Psychology of Pictorial Representation. New York: Phaidon Press.

Hanich, Julian. 2014. Complex Staging: The Hidden Dimension of Roy Andersson's Aesthetics. Movie: A Journal of Film Criticism vol. 5: 37-49.

Larson, Mariah and Andres Marklund, eds. 2010. Swedish Film: An Introduction and Reader. Lund: Nordic Academic Press.

Lessing, Ephraim Gotthold. 1887 [1766]. Laocoon: An Essay Upon the Limits of Painting and Poetry: With Remarks Illustrative of Various Points in the History of Ancient Art. Boston: Roberts Brothers.

Lindqvist, Ursula. 2016. Roy Andersson's Songs from the Second Floor: Contemplating the Art of Existence. Seattle and London: University of Washington Press.

Minissale, Gregory. 2009. Framing Consciousness in Art: Transcultural Perspectives. Amsterdam and New York: Rodopi.

Ratner, Megan. 2015. The "Trivialist Cinema” of Roy Andersson: An Interview. Film Quarterly vol. 69, no. 1. https://filmquarterly.org/2015/09/24/thetrivialist-cinema-of-roy-andersson-an-interview. Last accessed 16. 09. 2017.

Spigland, Ethan. 2010. No Shadows to Hide In: A Conversation with Roy Andersson. 
https://orbismediologicus.wordpress.com/2010/09/12/no-shadows-to-hide-ina-conversation-with-roy-andersson/. Last accessed 29. 05. 2018.

Tuan, Yi-Fu. 1977. Space and Place: The Perspective of Experience. Minneapolis and London: The University of Minnesota Press.

Vishnevestsky, Ignatiy. 2009. Figurative and Abstract: An Interview with Roy Andersson. https://mubi.com/notebook/posts/figurative-and-abstract-aninterview-with-roy-andersson. Last accessed 16. 09. 2017.

Yang, Julianne Qiuling Ma. 2013. Towards a Cinema of Contemplation: Roy Andersson's Aesthetics and Ethics. https://www.academia.edu/11526218/ Towards_a_cinema_of_contemplation_Roy_Andersson_aesthetics_and_ ethics_complete_thesis. Last accessed 22. 02. 2017.

\section{List of Figures}

Figures 1-2. Empty cloakroom during a celebration; overcrowded elevator at rush hour. (A Pigeon, 2014).
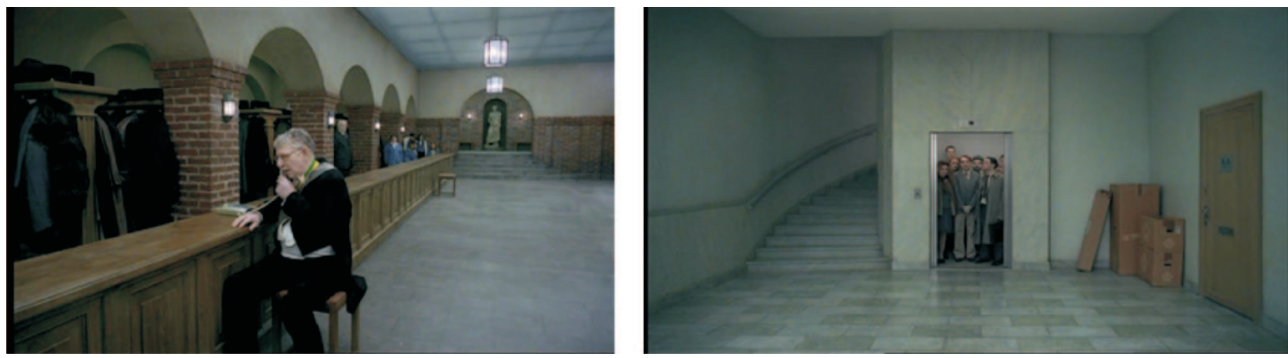

Figures 3-4. The men, downstairs and upstairs, linked by sound (You, 2007).
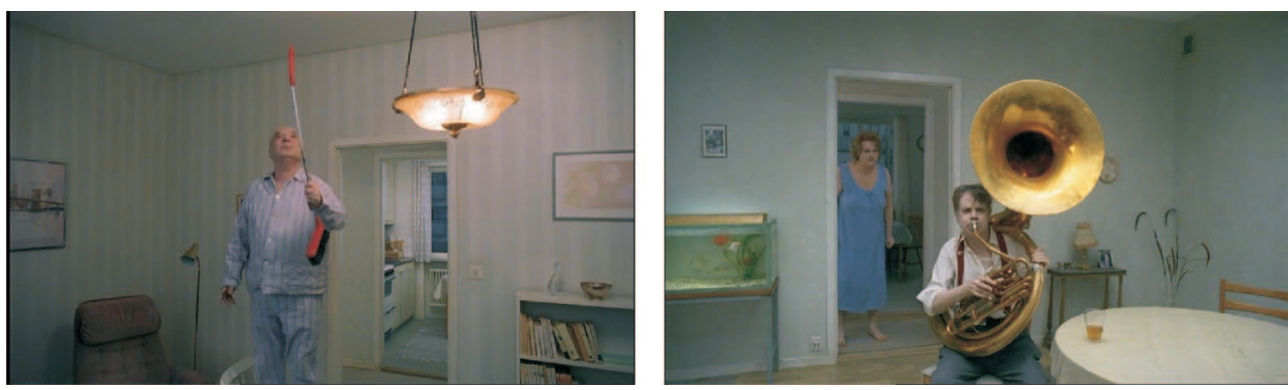
Figure 5. Injecting depth into a flat surface (A Pigeon, 2014). Figure 6. Scanning the image layers in depth (You, 2007).
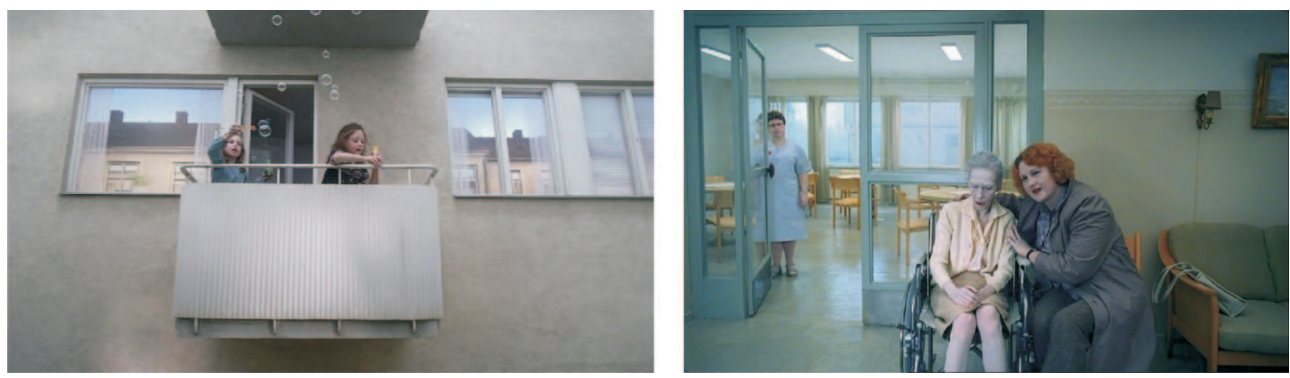

Figures 7-8. Renaissance artificiality centre stage; bouncing the viewer's gaze across frames (A Pigeon, 2014).
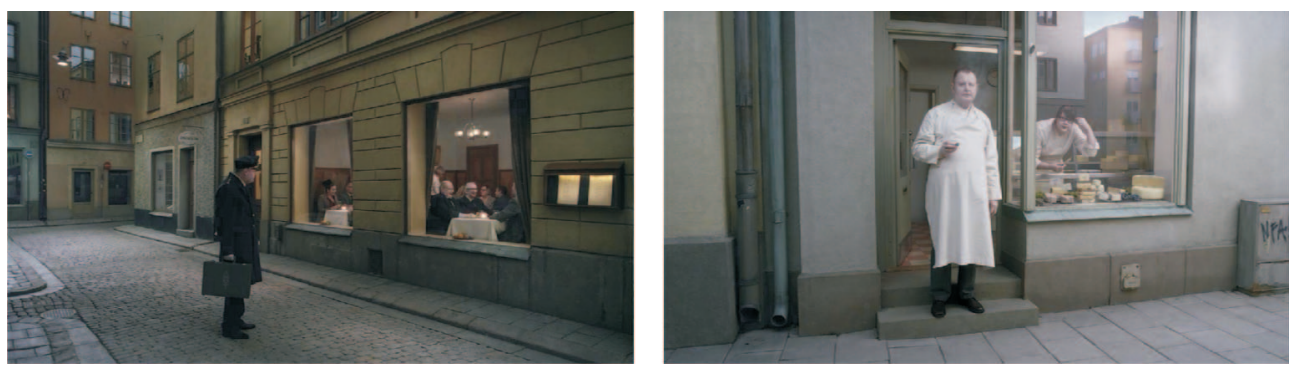

Figures 9-10. A pigeon, off screen, "watches" humanity; a crammed onscreen space, conveying consecutiveness within simultaneity (A Pigeon, 2014, and You, 2007).
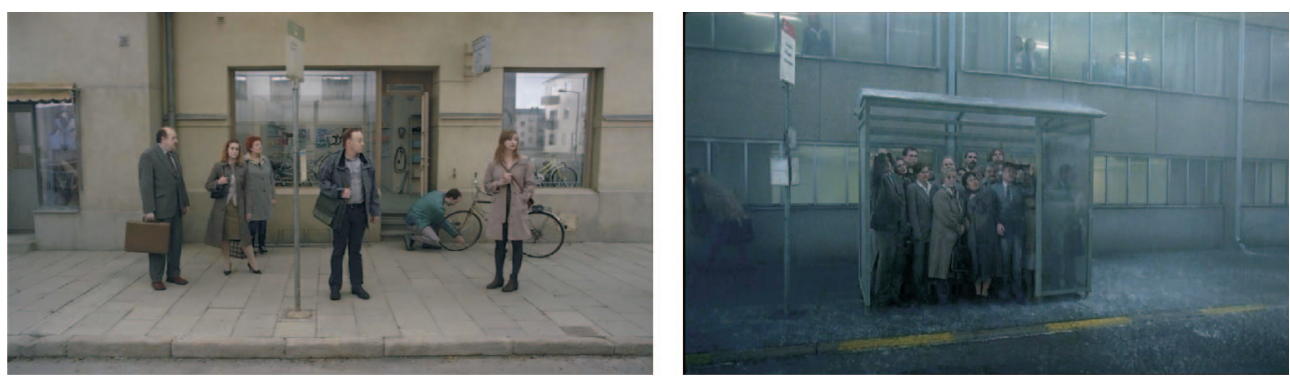
Figures 11-12. The action that keeps on going; expanding time through anguish (You, 2007, and A Pigeon, 2014).
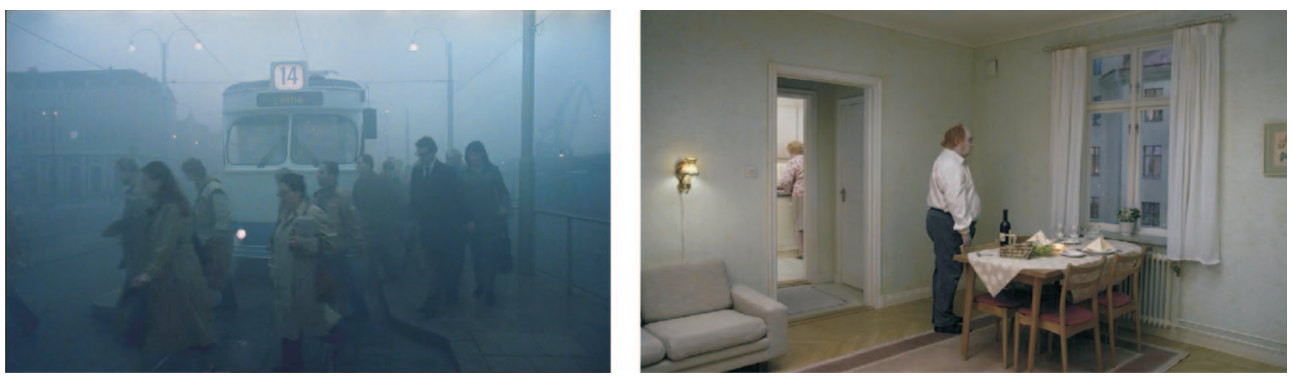

Figures 13-14. The ongoing shot that has no action (You, 2007).
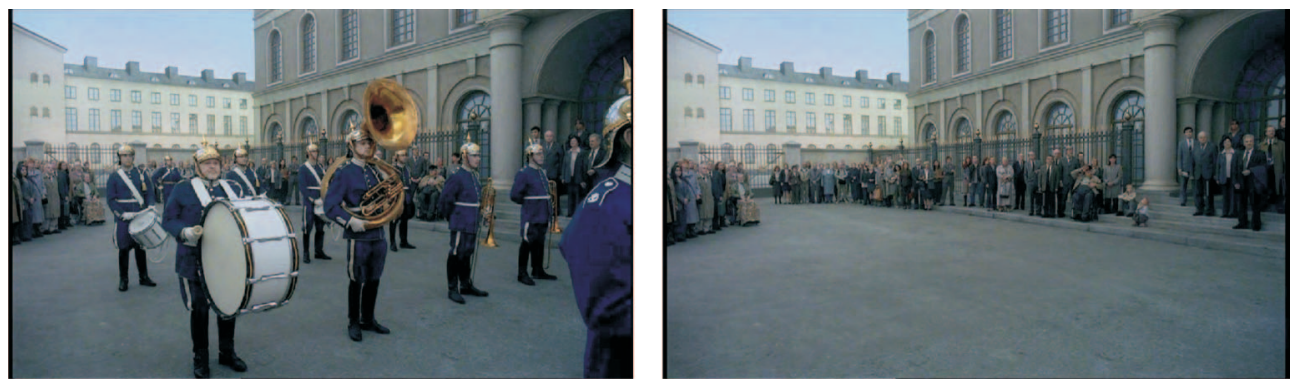